\title{
Onset and disappearance rates of gastroesophageal reflux symptoms in the Spanish population, and their impact on quality of life
}

\author{
E. Rey, A. Álvarez-Sánchez, F. Rodríguez-Artalejoํ, C. Moreno Elola-Olaso, C. Almansa \\ and M. Díaz-Rubio
}

Division of Digestive Diseases. Hospital Clínico San Carlos. Complutense University. Madrid, Spain. ${ }^{1}$ Department of Preventive Medicine and Public Health. School of Medicine. Universidad Autónoma de Madrid. CIBER of Epidemiology and Public Health (CIBERESP). Spain

\begin{abstract}
Background: few studies have reported the onset and disappearance rates of gastroesophageal reflux symptoms (GERS) in the population.

Aim: to assess the occurrence and disappearance rates of GERS in Spain, and their impact on health-related quality of life (HRQL).

Participants and methods: participants were selected at random from the general population of Madrid in age and sex strata. They were interviewed at home twice, 6 months apart. Heartburn, acid regurgitation and consultation were assessed with the gastroesophageal reflux questionnaire, and HRQL with the SF-36.

Results: 709 individuals were included, and 451 (63.6\%) were re-interviewed 6 months later. Among the 325 individuals without GERS, 9 developed weekly symptoms (2.2\% [95\% CI: $0.8,3.4 \%]$ ); 2 (22\%) consulted because of GERS. Among the 34 subjects reporting weekly GERS initially, 26 did not report them at 6-months. Onset of GERS was associated with worsening scores in the physical summary of SF-36 (delta $=-6.6[95 \%$ CI: $-11.8,-1.42]$ ), while disappearance with an improved score (delta $=-3.0$ [95\% CI: 0.0, 5.9]).

Conclusion: despite the lower prevalence of GERS in Spain, the occurrence rate is $2.2 \%$ in 6 months; however symptoms disappeared in more than half of subjects six months later. Developing GERS was associated with reduced HRQL, and their disappearance with improvement.
\end{abstract}

Key words: Gastroesophageal reflux. Quality of life.

Financial support: this study was supported by an unrestricted grant from the Mutua Madrileña Foundation.

Received: 03-03-09.

Accepted: 17-04-09.

Correspondence: Enrique Rey. Servicio de Aparato Digestivo. Hospital Clínico San Carlos. C/ Martín Lagos, s/n. 28040 Madrid, Spain. e-mail: rey.enrique.spain@gmail.com
Rey E, Álvarez-Sánchez A, Rodríguez-Artalejo F, Moreno Elola-Olaso C, Almansa C, Díaz-Rubio M. Onset and disappearance rates of gastroesophageal reflux symptoms in the Spanish population, and their impact on quality of life. Rev Esp Enferm Dig 2009; 101: 477-482.

\section{INTRODUCTION}

Several cross sectional surveys have shown that gastroesophageal reflux symptoms (GERS) are frequent in Western populations, with a prevalence ranging from 10 to $30 \%(1,2)$, and with substantial geographic differences (3). However, information regarding GERS onset is scarce. An analysis of primary care databases reported a gastroesophageal reflux disease (GERD) incidence of 4.5 and 5.4 per 1,000 person-years $(4,5)$, though these data represent only the incidence of subjects newly diagnosed with the disease, and might be highly dependent on consultation behavior.

Also the incidence of GERS in the general population has been estimated in a few studies. In 1992, Talley et al. provided the first population-based estimation, reporting an incidence of 43 persons-year with weekly GERS in white Americans (6). Two studies have reported an incidence of GERS of 3\% at 3 months (7) and 2.2-2.6\% yearly (8) in Scandinavian populations. Moayyedi et al. reported a 3\% incidence of frequent GERS at 2 years in a British population (9). Finally, in Asians the onset of newly weekly GERS has been estimated at $1.5 \%$ yearly with an incidence of monthly GERS of $4 \%$ at one year (10).

Since GERS are known to come and go, both their onset and the disappearance rates are important to understand the dynamics of GERS over time. To date, only three studies have reported the disappearance rate of GERS, providing figures of 353 per 1,000 persons-year (6), 
243 per 1000 persons-year (monthly symptoms) (10), and a $59-77 \%$ disappearance rate of frequent heartburn at one year (7).

GERS are associated with a worse health-related quality of life (HRQOL) in community subjects (11-13), but it is unknown to what extent it is directly related to the occurrence of symptoms since no follow-up information exists. Also adequate treatment of GERS leads to HRQL improvement $(14,15)$, but it has not been established whether it also occurs with the spontaneous disappearance of symptoms.

The prevalence of GERS keeps a steady level in the population along a short period of time. In that situation, prevalence is directly related to occurrence and inversely related to disappearance, so both parameters are important to understand the differences in prevalence of GERS worldwide. Thus, the main aim of our study was to estimate the occurrence and disappearance rates of GERS at 6 months in the Spanish population. Also, we aimed at assessing the consultation behavior induced by GERS, as well as the changes in HRQL associated with modifications in symptomatic status.

\section{PARTICIPANTS AND METHODS}

Study participants were selected through random sampling, stratified by age and sex, from the 2003 population census of Madrid. In total, 709 individuals were interviewed at home between April 2005 and June 2005. Six months later, responders to the first interview were invited to a follow-up interview. All interviews were done by professional personnel trained specifically in the study methods. A quarter of all interviews were reviewed by study supervisors through phone calls, to check inconsistencies and other aspects of data quality.

The study was approved by the Hospital Clínico San Carlos Ethics Committee, and all individuals signed an informed consent to participate.

Data on GERS were obtained with the Gastro-Esophageal Reflux Questionnaire (16) (GERQ), validated for use in the Spanish population (17). This questionnaire comprises 80 questions organized into sections, and a list of psychosomatic symptoms, referring to the preceding year. Heartburn was defined as a burning feeling that rises through the chest, and acid regurgitation as liquid coming back into the mouth leaving a bitter or sour taste. A subject was deemed to suffer GERS when he/she reported heartburn and/or acid regurgitation, irrespective of its frequency, severity or duration. Symptoms were defined as "frequent" if they occurred at least weekly and "occasional" if they occurred less frequently. The frequency was defined, in each case, in terms of the individual characteristics of heartburn and acid regurgitation, taking the more frequent when both symptoms were reported. Symptom recall time was one year during the baseline interview and 6 months at the follow-up interview.
GERQ also collects information on the frequency of use of antisecretory drugs, both proton-pump inhibitors (PPIs) and H2-blockers, which was checked against the medication packages. Study participants were also asked whether they had attended a medical consultation because of heartburn or acid regurgitation. Lastly, the SF-36, a generic HRQL instrument, was also used at the baseline and follow-up interviews. SF-36 is a widely used, generic instrument for measuring HRQOL. We used the validated Spanish version (18), which has been shown to be equivalent to the original and other translations (19). Scores relative to the normative population were obtained for the eight SF-36 dimensions (physical functioning, rolephysical, bodily pain, vitality, general health, social functioning, role-emotional, and mental health) that are summarized in two composite scores (physical and mental). For each SF-36 scale, and for the physical and mental summaries, the scores ranged from 0 to 100 . In all cases, the higher the score, the better was HRQL.

A prevalent case was defined as the reporting of GERS at the time of the baseline interview. An incident case was defined as the reporting of GERS at the follow-up interview among participants who were GERS-free at baseline. GERS were considered to disappear when the subjects reported them at the first interview but not in the follow-up interview. Occurrence and disappearance rates were calculated on the basis of reporting weekly GERS.

Six-month changes in the physical and mental summary scores of the SF-36 were tested with the paired Wilcoxon's test.

\section{RESULTS}

Among the 2,652 individuals invited to participate, 709 accepted, 524 accepted but were rejected because their strata were already completed, and 1,419 refused to participate. A total of 451 of the 709 participants completed the follow-up interview 6 months later. Thus, the response rate for the initial interview was $46.5 \%$, and the acceptance rate for follow-up was $63.6 \%$. No substantial differences in socio-demographic variables, reflux symptom characteristics, risk factors of GERS, and medications used were found between those who completed the follow-up interview and those who did not, except a higher proportion of women among those who were followed up (Table I).

\section{Prevalence of GERS}

Among the 709 subjects who completed the first interview, 60 reported weekly GERS $(8.5 \%$; $95 \%$ CI 6.4 to $10.5 \%)$, and 136 less than weekly symptoms (19.2\%; $95 \%$ CI 16.3 to $22.1 \%$ ). 
Table I. Characteristics of participants completing and not completing follow-up at 6 months

\begin{tabular}{|c|c|c|}
\hline & \multicolumn{2}{|c|}{ Completed follow-up } \\
\hline & No $(n=258)$ & Yes $(n=451)$ \\
\hline $\begin{array}{l}\text { Gender (females)* } \\
\text { Age (years) }\end{array}$ & $\begin{array}{r}127(49.2 \%) \\
46.2 \pm 18.9\end{array}$ & $\begin{array}{c}259(57.4 \%) \\
44.4 \pm 17.2\end{array}$ \\
\hline $\begin{array}{l}\text { Marital status } \\
\text { Married } \\
\text { Single } \\
\text { Other }\end{array}$ & $\begin{array}{l}127(49.2 \%) \\
88(34.1 \%) \\
43(16.7 \%)\end{array}$ & $\begin{array}{l}225(49.9 \%) \\
148(32.8 \%) \\
78(17.3 \%)\end{array}$ \\
\hline $\begin{array}{l}\text { Education level } \\
\text { School } \\
\text { High school } \\
\text { College }\end{array}$ & $\begin{array}{l}87(33.7 \%) \\
112(43.4 \%) \\
59(22.9 \%)\end{array}$ & $\begin{array}{l}145(32.2 \%) \\
192(42.6 \%) \\
114(25.3 \%)\end{array}$ \\
\hline $\begin{array}{l}\text { Working status } \\
\text { Working } \\
\text { Unemployed }\end{array}$ & $\begin{array}{c}145(56.2 \%) \\
24(9.3 \%)\end{array}$ & $\begin{array}{c}280(62.1 \%) \\
27(6.0 \%)\end{array}$ \\
\hline $\begin{array}{l}\text { Retired } \\
\text { Housewife } \\
\text { Student }\end{array}$ & $\begin{array}{c}42(16.3 \%) \\
31(12.0 \%) \\
16(6.2 \%)\end{array}$ & $\begin{array}{l}49(10.9 \%) \\
63(14.0 \%) \\
32(7.1 \%)\end{array}$ \\
\hline $\begin{array}{l}\text { Smoking } \\
\text { Never } \\
\text { Former } \\
\text { Current }\end{array}$ & $\begin{array}{l}134(51.9 \%) \\
42(16.3 \%) \\
82(31.8 \%)\end{array}$ & $\begin{array}{l}251(55.7 \%) \\
53(11.8 \%) \\
147(32.6 \%)\end{array}$ \\
\hline $\begin{array}{l}\text { Alcohol } \\
\text { Never or rarely } \\
1-6 \text { drinks per week } \\
\text { Daily or more }\end{array}$ & $\begin{array}{l}135(52.3 \%) \\
95(36.8 \%) \\
28(10.9 \%)\end{array}$ & $\begin{array}{l}249(55.2 \%) \\
168(37.3 \%) \\
34(7.5 \%)\end{array}$ \\
\hline $\begin{array}{l}\text { NSAID use } \\
\text { Family history } \\
\text { of esophago-gastro-duodenal diseases } \\
\text { of gastroesophageal reflux }\end{array}$ & $\begin{array}{l}22(8.5 \%) \\
29(11.2 \%) \\
6(2.3 \%)\end{array}$ & $\begin{array}{l}27(6.0 \%) \\
29(6.4 \%) \\
16(3.5 \%)\end{array}$ \\
\hline $\begin{array}{l}\text { Spouse history } \\
\text { of esophago-gastro-duodenal diseases } \\
\text { of gastroesophageal reflux }\end{array}$ & $\begin{array}{c}9(3.5 \%) \\
10(3.9 \%)\end{array}$ & $\begin{array}{l}15(3.3 \%) \\
11(2.4 \%)\end{array}$ \\
\hline $\begin{array}{l}\text { Use H2 Blockers } \\
\text { Use of PPI } \\
\text { Body mass index }\left(\mathrm{kg} / \mathrm{m}^{2}\right) \\
\text { Psychosomatic symptom score } \\
\text { Gastroesophageal reflux symptoms }\end{array}$ & $\begin{array}{c}16(6.2 \%) \\
39(15.1 \%) \\
26.3 \pm 5.0 \\
11.3 \pm 12.6\end{array}$ & $\begin{array}{c}26(5.8 \%) \\
58(12.9 \%) \\
26.2 \pm 5.3 \\
10.6 \pm 12.2\end{array}$ \\
\hline $\begin{array}{l}\text { Any frequency } \\
\text { Weekly }\end{array}$ & $\begin{array}{l}70(27.1 \%) \\
26(10.1 \%)\end{array}$ & $\begin{array}{c}126(27.9 \%) \\
34(7.5 \%)\end{array}$ \\
\hline
\end{tabular}

For continuous variables, mean \pm standard deviation is provided; ${ }^{*} \mathrm{p}<0.05$ Fischer's test. NSAID: non-steroidal anti-inflammatory drug; PPI: proton pump inhibitors.

\section{Occurrence of GERS}

Among the 325 individuals without GERS at baseline, $21(6.5 \% ; 95 \%$ CI 3.2 to $9.2 \%)$ reported less than weekly symptoms and $5(1.5 \%$; $95 \%$ CI 0.2 to $2.8 \%)$ weekly symptoms 6 months later. Among the 92 subjects with less than weekly symptoms at the baseline interview, $4(4.3 \%$; $95 \%$ CI 0.1 to $8.5 \%)$ reported weekly symptoms 6 months later. In all, among the 417 subjects without GERS or occasional GERS at baseline, 9 developed weekly symptoms during the 6-month follow up, corresponding to an onset rate of $2.2 \%$ (95\% CI 0.8 to $3.4 \%$ ) per 6 months.

In all, 9 subjects developed weekly symptoms, $26 \mathrm{im}$ proved (either disappeared or became occasional), 8 remained with weekly symptoms and 408 kept without symptoms or they were only occasional. Table II shows differences between these groups of subjects in socio-demographic and anthropometric variables, and in known risk factor of GERS.

\section{Medical consultation because of GERS}

At baseline, 28 of 126 (22.2\%) subjects with occasional or weekly GERS reported having consulted with their physician in the preceding year. Eight of 30 subjects (26.6\%) with new-onset GERS visited the doctor because of GERS; of them, 6 had developed less than weekly symptoms and 2 weekly symptoms. Just 2 subjects had a diagnostic test ordered. As for the whole sample, 2 subjects developed weekly GERS and were evaluated by a physician (a proxy of diagnosis with GERD); that represents $0.44 \%$ of the whole sample in a six-month period.

\section{Disappearance rate of GERS}

Among the 92 individuals with less than weekly symptoms at the baseline interview, $66(71.2 \%$; 95\% CI 62.5 to $80.9 \%$ ) did not report GERS 6 months later. Among the 34 subjects with weekly symptoms at baseline, 20 reported no symptoms and 6 reported less than weekly symptoms 6 months later. Among those with weekly GERS at baseline, PPI therapy was reported by only 6 subjects whose symptoms disappeared. In analyses excluding those without PPI therapy, the disappearance rate of GERS was $58.8 \%$ (95\% CI 42.2 to $75.3 \%$ ) at 6 months.

\section{Impact of onset and disappearance of GERS on quality of life}

As shown in table III, onset of weekly GERS was associated with a significant worsening in the physical summary of the SF-36 ( $\Delta=-6.6 ; 95 \%$ CI -11.8 to -1.42$)$. In contrast, the disappearance of weekly GERS was associated with an improvement in the physical summary $(\Delta$ $=3.0 ; 95 \%$ CI 0.0 to 5.9$)$.

\section{DISCUSSION}

Our study provides, for the first time, figures on the onset and disappearance rates of GERS in a Mediterrane- 
Table II. Socio-demographic and anthropometric variables, and risk factors of gastroesophageal reflux symptoms (GERS), according to changes in GERS over the six-month follow-up

\begin{tabular}{|c|c|c|c|c|}
\hline & $\begin{array}{l}\text { Remained without } \\
\text { GERS }(n=408)\end{array}$ & $\begin{array}{c}\text { GERS disappeared } \\
(n=26)\end{array}$ & $\begin{array}{l}\text { Onset of GERS } \\
\quad(n=9)\end{array}$ & $\begin{array}{l}\text { Remained with } \\
\text { GERS }(n=8)\end{array}$ \\
\hline Gender ( $\%$ females) & $55.9 \%$ & $80.8 \%$ & $55.6 \%$ & $62.5 \%$ \\
\hline Age (years) & $44.7 \pm 17.4$ & $45.2 \pm 17.4$ & $35.1 \pm 18.4$ & $39.1 \pm 9.8$ \\
\hline Change in PSC & $-3.0 \pm 9.7$ & $-11.6 \pm 18.1$ & $-1.4 \pm 10.2$ & $-4.5 \pm 18.7$ \\
\hline BMI at baseline & $26.0 \pm 5.0$ & $27.5 \pm 7.2$ & $28.6 \pm 7.8$ & $27.7 \pm 6.4$ \\
\hline Change in weight & $0.2 \pm 3.9$ & $-2.4 \pm 10.8$ & $1.1 \pm 5.3$ & $0.1 \pm 2.3$ \\
\hline$\%$ with occasional GERS at baseline & $21.6 \%$ & - & $44.1 \%$ & - \\
\hline Family history of GERD/EGD & $9.1 \%$ & $11.5 \%$ & $22.2 \%$ & $25 \%$ \\
\hline \multicolumn{5}{|l|}{ NSAID use } \\
\hline No intake & $92.1 \%$ & $84.6 \%$ & $100 \%$ & $75 \%$ \\
\hline Onset of intake & $2.4 \%$ & $3.8 \%$ & $0 \%$ & $0 \%$ \\
\hline Ceases the intake & $3.9 \%$ & $11.5 \%$ & $0 \%$ & $0 \%$ \\
\hline Keep the intake & $1.2 \%$ & $0 \%$ & $0 \%$ & $25 \%$ \\
\hline
\end{tabular}

PSC: psychosomatic symptom score; BMI: body mass index; GERD: gastroesophageal reflux disease; EGD: esophago-gastric diseases.

Table III. Impact of change in weekly gastroesophageal reflux symptoms (GERS) on the physical and mental summary scores of the SF-36 questionnaire over a sixmonth follow-up

\begin{tabular}{lccc}
\hline & Basal interview & $\begin{array}{c}\text { Follow-up } \\
\text { interview }\end{array}$ & p value* \\
\hline Physical summary score & & & \\
$\quad$ Remained without GERS $(n=408)$ & $51.9 \pm 8.1$ & $52.5 \pm 7.4$ & 0.2 \\
Disappearance of GERS $(n=26)$ & $47 . .8 \pm 8.4$ & $50.8 \pm 7.8$ & 0.04 \\
Onset of GERS $(n=9)$ & $53.6 \pm 8.2$ & $47.0 \pm 8.0$ & 0.007 \\
Remained with GERS $(n=8)$ & $43.5 \pm 11.8$ & $49.7 \pm 9.0$ & 0.07 \\
& & & \\
Mental summary score & & & \\
$\quad$ Remained without GERS $(n=408)$ & $51.1 \pm 8.4$ & $52.0 \pm 6.7$ & 0.3 \\
Disappearance of GERS $(n=26)$ & $44.5 \pm 12.4$ & $50.8 \pm 8.0$ & 0.01 \\
Onset of GERS $(n=9)$ & $45.5 \pm 12.9$ & $52.8 \pm 7.8$ & 0.07 \\
Remained with GERS $(n=8)$ & $45.9 \pm 12.2$ & $48.9 \pm 13.2$ & 0.3 \\
\hline *Wilcoxon's test. & &
\end{tabular}

*Wilcoxon's test.

an population, as well as information on the changes in HRQL associated with GERS onset and disappearance.

The onset rate of GERS might be a good estimate of its true incidence, since our study sample was designed to be representative of the population of Madrid. Although Madrid does not necessarily reflect the whole country, previous research in Spain did not show any difference in the prevalence or characteristics of GERS between rural and urban media, or any other geographical variation (2). The onset rate of $2.2 \%$ at 6 months may reasonably correspond to an annual rate around $4 \%$. This figure is similar to the $4.4 \%$ incidence rate reported in the US (6). Thus, it is not likely that the lower prevalence of GERS in Spain (2) versus the US (1) is due to a lower incidence of GERS.

The disappearance of GERS is the other factor determining its prevalence in the population. Our estimate of the disappearance rate of GERS should be considered with caution due to the small number of subjects with weekly symptoms at baseline. Although it is difficult to estimate confidently the annual rate, it seems to be higher than the $37 \%$ reported in the US (6). In view of these results, we hypothesize that the disappearance rate of GERS is an important contributor to the differences in the prevalence of GERS across populations, with equal or greater importance than the incidence rate. Future studies should confirm this hypothesis.

Figures for incident cases of GERS are similar to those in Great Britain from primary care databases (20), which are a good reference for Spain because of the similar high rate of consultation, around $25 \%$ per year (21). We used as a proxy of newly diagnosed GERD those cases with weekly symptom onset who consulted with a physician because of them. It suggests a rate of new GERD diagnosis around $0.5-1 \%$ in an environment with a $25 \%$ consultation rate for reflux symptoms yearly. Areas with lower consultation rates would have a lower rate of new diagnoses of GERD, but this remains to be shown.

Current guidelines for managing GERD (22-24) recommend a limited work-up initially in patients consulting their primary care physician for GERS. Although our study does not formally intend to explore how Spanish physicians follow these guidelines, it clearly shows that the use of diagnostic tests for GERD in Spain is fairly low. Moreover, our results strongly support this approach, since the high spontaneous disappearance rate in the short term implies that procedures are unneeded in most cases.

Cross-sectional surveys have shown that a family history of GERS, overweight, and PSS scores are the main risk factors for GERS $(2,25)$. Only one study, however, has reported which factors predict the onset of new symptoms, showing that anxiety and high educational level were longitudinally associated with the onset of GERS (10). Weight gain was associated with GERS of short duration (1 year or less) (26) and such factor also predicted GERS during pregnancy in a longitudinal 
study. Although our sample size does not allow us to draw firm conclusions, our results suggest that weight gain, occasional GERS, and a family history are predictors of GERS onset, while female gender, losing weight, and a reduction in PSS were associated with a higher rate of disappearance. Knowledge of factors associated with the onset and the disappearance of GERS, especially regarding weight changes, is important for developing preventing strategies; thus our results encourage the conduct of a larger study.

GERS are associated to a lower HRQL in the population (11-13), but no study yet has evaluated the change in HRQL associated with the natural course of symptoms. Despite our small sample size, GERS onset was clearly associated with a worsening in physical scores, while GERS disappearance led to improved physical and mental scores; moreover, HRQL did not change in those who did not modify their GERS status. It is consistent with results from therapeutic trials $(14,15)$, and goes further to the simple cross-sectional identification of lower HRQL in persons with GERS. Therefore, our results suggest that symptomatic changes may be responsible for HRQL changes; they should, nevertheless, be confirmed by larger longitudinal studies with multivariate analyses, including as potential confounders psychosocial factors, which actually could explain both symptom development and the changes in HRQL.

Our study also confirms a prevalence of GERS around $10 \%$ in Spain. Two earlier studies reported conflicting results: one with a prevalence of $10 \%$ of weekly GERS (2), and another study with a prevalence of $15 \%$ for 2 or more symptomatic days per week (28). The low response rate might be related to the higher prevalence found in the second study.

The main limitation of our study was the small sample size, as already discussed. It precluded a full multivariate analysis and reduced the strength of conclusions. Also, the low response rate is a limitation; however, the fact that baseline data were consistent with those from previous studies (2) lends certain credibility to our results.

In conclusion, despite the lower prevalence of weekly GERS in Spain, the occurrence rate of GERS was similar to that seen in other Western societies. However, symptoms spontaneously disappeared in more than half of subjects six months later. This calls for some moderation in performing aggressive procedures to diagnose GERS. Lastly, developing GERS was associated with reduced HRQL, and GERS disappearance with improved HRQL scores.

\section{REFERENCES}

1. Locke GR, III, Talley NJ, Fett SL, Zinsmeister AR, Melton LJ, III. Prevalence and clinical spectrum of gastroesophageal reflux: a population-based study in Olmsted County, Minnesota. Gastroenterology 1997; 112: 1448-56.
2. Díaz-Rubio M, Moreno-Elola-Olaso C, Rey E, Locke GR, III, Rodríguez-Artalejo F. Symptoms of gastro-oesophageal reflux: prevalence, severity, duration and associated factors in a Spanish population. Aliment Pharmacol Ther 2004; 19: 95-105.

3. Dent J, El-Serag HB, Wallander MA, Johansson S. Epidemiology of gastro-oesophageal reflux disease: a systematic review. Gut 2005; 54: 710-17.

4. Ruigómez A, García Rodríguez LA, Wallander MA, Johansson S, Graffner H, Dent J. Natural history of gastro-oesophageal reflux disease diagnosed in general practice. Aliment Pharmacol Ther 2004; 20: 751-60

5. Kotzan J, Wade W, Yu HH. Assessing NSAID prescription use as a predisposing factor for gastroesophageal reflux disease in a Medicaid population. Pharm Res 2001; 18: 1367-72.

6. Talley NJ, Weaver AL, Zinsmeister AR, Melton LJ, III. Onset and disappearance of gastrointestinal symptoms and functional gastrointestinal disorders. Am J Epidemiol 1992; 136: 165-77.

7. Agreus L, Svardsudd K, Nyren O, Tibblin G. Irritable bowel syndrome and dyspepsia in the general population: overlap and lack of stability over time. Gastroenterology 1995; 109: 671-80.

8. Kay L, Jorgensen T, Jensen KH. Epidemiology of abdominal symptoms in a random population: prevalence, incidence, and natural history. Eur J Epidemiol 1994; 10: 559-66.

9. Moayyedi P, Axon AT. Review article: gastro-oesophageal reflux disease--the extent of the problem. Aliment Pharmacol Ther 2005; 22(Supl. 1): 11-9.

10. Wong WM, Lai KC, Lam KF, Hui WM, Huang JQ, Xia HH, et al. Onset and disappearance of reflux symptoms in a Chinese population: a 1-year follow-up study. Aliment Pharmacol Ther 2004; 20 : 803-12.

11. Revicki DA, Wood M, Maton PN, Sorensen S. The impact of gastroesophageal reflux disease on health-related quality of life. Am J Med 1998; 104: 252-8.

12. Frank L, Kleinman L, Ganoczy D, McQuaid K, Sloan S, Eggleston A, et al. Upper gastrointestinal symptoms in North America: prevalence and relationship to healthcare utilization and quality of life. Dig Dis Sci 2000; 45: 809-18.

13. Ronkainen J, Aro P, Storskrubb T, Lind T, Bolling-Sternevald E, Junghard $\mathrm{O}$, et al. Gastro-oesophageal reflux symptoms and healthrelated quality of life in the adult general population--the Kalixanda study. Aliment Pharmacol Ther 2006; 23: 1725-33.

14. McDougall NI, Collins JS, McFarland RJ, Watson RG, Love AH. The effect of treating reflux oesophagitis with omeprazole on quality of life. Eur J Gastroenterol Hepatol 1998; 10: 459-64.

15. Kulig M, Leodolter A, Vieth M, Schulte E, Jaspersen D, Labenz J, et al. Quality of life in relation to symptoms in patients with gastro-oesophageal reflux disease-- an analysis based on the ProGERD initiative. Aliment Pharmacol Ther 2003; 18: 767-76.

16. Locke GR, Talley NJ, Weaver AL, Zinsmeister AR. A new questionnaire for gastroesophageal reflux disease. Mayo Clin Proc 1994; 69: $539-47$.

17. Moreno Elola-Olaso C, Rey E, Rodriguez-Artalejo F, Locke GR, III, Diaz-Rubio M. Adaptation and validation of a gastroesophageal reflux questionnaire for use on a Spanish population. Rev Esp Enferm Dig 2002; 94: 745-58.

18. Alonso J, Regidor E, Barrio G, Prieto L, Rodriguez C, de la FL. Population reference values of the Spanish version of the Health Questionnaire SF-36. Med Clin (Barc) 1998; 111: 410-6.

19. Wagner AK, Gandek B, Aaronson NK, Acquadro C, Alonso J, Apolone $\mathrm{G}$, et al. Cross-cultural comparisons of the content of SF-36 translations across 10 countries: results from the IQOLA Project. International Quality of Life Assessment. J Clin Epidemiol 1998; 51: 925-32.

20. Kennedy T, Jones R. The prevalence of gastro-oesophageal reflux symptoms in a UK population and the consultation behaviour of patients with these symptoms. Aliment Pharmacol Ther 2000; 14: 1589-94.

21. Rey E, Moreno-Elola-Olaso C, Rodríguez-Artalejo F, Díaz-Rubio M. Medical consultation for gastro-oesophageal reflux symptoms: reasons and associated factors. Digestion 2004; 70: 173-7.

22. Marzo M, Alonso P, Bonfill X, Fernandez M, Ferrandiz J, Martinez $\mathrm{G}$, et al. Clinical practice guideline on the management of patients with gastroesophageal reflux disease (GERD). Gastroenterol Hepatol 
2002; 25: 85-110.

23. Armstrong D, Marshall JK, Chiba N, Enns R, Fallone CA, Fass R, et al. Canadian Consensus Conference on the management of gastroesophageal reflux disease in adults - update 2004. Can J Gastroenterol 2005; 19: 15-35.

24. DeVault KR, Castell DO. Updated guidelines for the diagnosis and treatment of gastroesophageal reflux disease. Am J Gastroenterol 2005; 100: 190-200.

25. Locke GR, III, Talley NJ, Fett SL, Zinsmeister AR, Melton LJ, III. Risk factors associated with symptoms of gastroesophageal reflux. Am J Med 1999; 106: 642-9.
26. Rey E, Moreno-Elola-Olaso C, Artalejo FR, Locke GR, III, Díaz-Rubio $\mathrm{M}$. Association between weight gain and symptoms of gastroesophageal reflux in the general population. Am J Gastroenterol 2006; 101: 229-33.

27. Rey E, Rodríguez-Artalejo F, Herraiz MA, Sánchez P, Álvarez-Sánchez A, Escudero M, et al. Gastroesophageal reflux symptoms during and after pregnancy: a longitudinal study. Am J Gastroenterol 2007; 102: 2395-400

28. Ponce J, Vegazo O, Beltrán B, Jiménez J, Zapardiel J, Calle D, et al. Prevalence of gastro-oesophageal reflux disease in Spain and associated factors. Aliment Pharmacol Ther 2006; 23: 175-84 